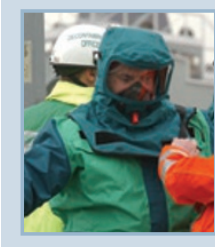

p1004 Unsafe science: Biodefense researchers need better training.

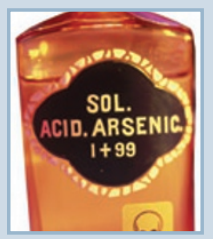

p1005 Costly cure: A cancer drug based on arsenic is too pricey for most people.

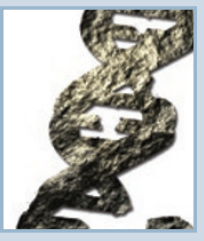

p1008 Death knell:

Gene therapy's future hangs in

the balance.

\title{
Alternative therapies finding acceptance in mainstream medicine
}

Christina Pike knew she had landed in the right place when, in her first year of medical school, a physiology lecturer handed out temperaturesensitive biofeedback stickers and led the class through a guided meditation.

The stickers would change color from green to deep blue as students relaxed, the lecturer explained. "Mine got a little closer to blue, though we were still in med school," Pike recalls. "I don't think you can get all the way there."

At age 20, Pike had cancer of the parotid gland and underwent surgery and radiation. But when she asked about alternative therapies, she says, her doctors weren't interested. She ended up seeking out art therapy and acupuncture on her own.

Now a second-year medical student at Georgetown University in Washington, DC, Pike says she sought out the prestigious university because of its emphasis on integrating complementary and alternative medicine (CAM) into the traditional curriculum.

Georgetown's seven-year effort includes an exchange program with a massage school, popular mind-body medicine courses, and the option to complete an additional degree in physiology with an emphasis on CAM, as Pike is doing.

"Physicians need to be prepared to be open to CAM and able to discuss it with their patients," says Pike. "I think Georgetown does a good job with that."

Georgetown is one of a growing number of US medical schools that are actively seeking to teach medical students about alternative therapies. The aim is not so much to teach the students to become herbalists or massage therapists as it is to expose them to a wide range of practices and help them communicate better with their patients.

Studies have shown that more than a third of Americans use alternative therapies, but more than half of those people don't feel comfortable confiding in their doctors about it (JAMA 280, 1569-1575; 1998).

The new programs also seek to educate medical students on how prescription drugs and herbal remedies might interact adversely and how to build relationships with their colleagues in complementary medicine, greasing referral

\section{wheels for later on.}

The Consortium of Academic Health Centers for Integrative Medicine, which includes the University of California at San Francisco and Duke, Harvard and Columbia Universities, is a key driver behind the movement. The consortium has grown from 11 founding members in 2002 to 38 this year, roughly a third of accredited North American medical schools.

At Duke University, a popular 'PDA boot camp' for medical students helps them mine the internet for information on botanicals and dietary supplements with handheld devices. Optional lunchtime lectures on acupuncture and meditation that once struggled for attendees are attended by more than half of first-year medical students.

That's not surprising, given the widespread and growing use of alternative therapies, says Aviad Haramati, founding vice chair of the consortium and a professor of physiology at Georgetown.

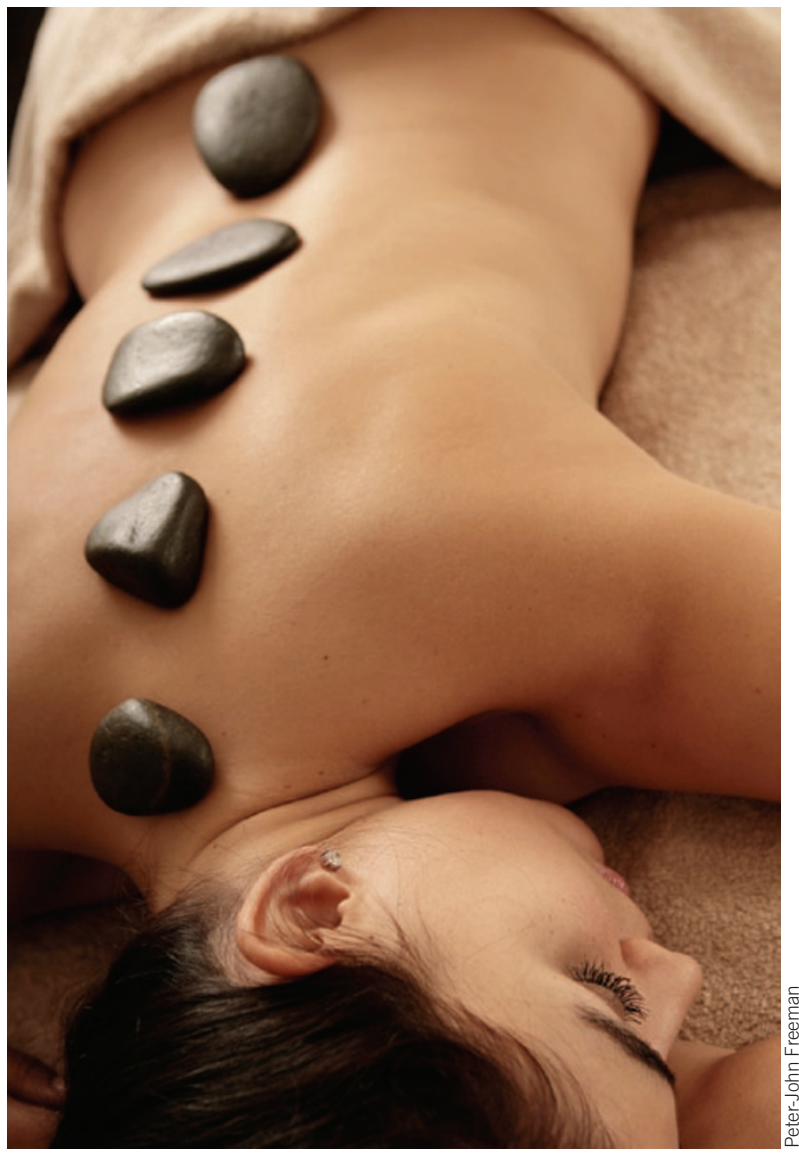

Soft science: Some medical schools are teaching students about alternative approaches such as accupuncture and massages.

"As soon as you come in contact with patients, you begin to realize that this is information that is important."

In a 2002 survey of the University of Minnesota's medical school faculty, for instance, $86 \%$ said CAM practices should be included in the curriculum. This year, $75 \%$ of medical students at Georgetown agreed (Altern. Ther. Health Med. 13, 30-35; 2007).

"[This] is going to advance medical education in ways that wouldn't be possible without it," says Haramati. "To bring in an acupuncturist or a massage therapist for the benefit of the patient requires a certain degree of humility and teamwork on the part of the physician. And isn't that what we want?"
Still, most medical students don't appear to believe in the CAM treatments' effectiveness. With the exception of acupuncture and chiropractics, fewer than half say they want to learn enough about other CAM approaches such as homeopathy, aromatherapy and biofeedback to advise their patients, let alone practice the techniques themselves.

Many students also bypass the courses unless they are required. "The way medical education is organized, you do what you have to do," says Maggie Kuhn, a second-year orthopedics resident at Washington University in St. Louis. "To be honest, by the time I got to the fourth year, if it wasn't required, my preferences just steered away from it."

Meredith Wadman, Washington, DC 